ISSN 0258-7122 (Print), 2408-8293 (Online)

Bangladesh J. Agril. Res. 42(3): 403-411, September 2017

\title{
MARKER ASSISTED INTROGRESSION OF BACTERIAL BLIGHT RESISTANT GENE INTO SUBMERGENCE TOLERANCE RICE VARIETY BRRI dhan52
}

\author{
M. E. KABIR ${ }^{1}$, K. M. IFTEKHARUDDAULA ${ }^{2}$, M. A. I. KHAN ${ }^{3}$ \\ M. A. K. MIAN ${ }^{4}$ AND N. A. IVY
}

\begin{abstract}
BRRI dhan52 is a uniquire submergence tolerant rice variety containing prominant genetic background of BR11, a mega rainfed lowland rice (RLR) variety of Bangladesh, but is susceptible to bacterial blight (BB) caused by Xanthomonas oryzae pv. oryzae (Xoo). The variety is considerably popular in the southern part of Bangladesh due to its high yield in flash flood condition and comparatvely medium slender grain. Molecular markers linked to BB resistance genes (Xa genes) and submergence QTL ( $S U B 1)$ were utilized in a marker-aided selection program to develop elite breeding lines with broad-spectrum resistance to bacterial blight. Sequence tagged site (STS) and simple sequence repeat (SSR) markers were essentially used to detect the genes for BB and submergence as well. In backcross generation, markers closely linked to $\mathrm{Xa21}$ and SUB1 QTL were used to select desirable plants possessing these resistance genes (foreground selection) and microsatellite markers polymorphic between donor and recurrent parent were also used to select plants that have maximum contribution from the recurrent parent genome (background selection). In $\mathrm{BC}_{1} \mathrm{~F}_{1}$ generation, three best plants consiquently were selected from previously selected ten double heterozygous ( $X a 21$ and SUB1 QTL) plants. The percentage of recipient genome recovery in the best plant 1,2 and 3 were $78.7 \%, 75.83 \%$ and $75.4 \%$, respectively. Eventually this work illustrates the successful application of marker-assisted breeding for introgression of bacterial blight resistant gene into a rice variety of Bangladesh.
\end{abstract}

Keywords: Bacterial blight, marker assisted backcrossing, Xa21 gene, SUB1 QTL, Rainfed lowland rice.

\section{Introduction}

Bacterial blight (BB) caused by Xanthomonas oryzae pv. oryzae (Xoo) is one of the most widespread and important diseases of rice in most of the rice growing countries due to its high epidemic potential and destructiveness to high yielding cultivars in both temperate and tropical region especially in Asia. It causes

\footnotetext{
${ }^{1}$ Agricultural Research \& Development Officer, CIAT-HarvestPlus, Bangladesh, ${ }^{2}$ Principal Scientific Officer, Plant Breeding Division, Bangladesh Agricultural Research Institute (BRRI), Gazipur, ${ }^{3}$ Principal Scientific Officer, Plant Pathology Division, BRRI, ${ }^{4}$ Professor, Department of Genetics and Plant Breeding, Bangabandhu Sheikh Mujibur Rahman Agricultural University (BSMRAU), Gazipur, ${ }^{5}$ Associates Professor, Department of Genetics and Plant Breeding, BSMRAU, Gazipur
} 
substantial yield loss ranging from $10 \%$ to $30 \%$ under field conditions (Reyes et al., 1983) and up to as high as $80 \%$ (Singh et al., 1997) and even 100\% under very severe conditions (Zhai and Zhu, 1999). Though BB is controlled by various means, host plant resistance is considered to be the most effective, economical and environmentally safe option for management of the BB pathogen (Khush et al., 1989).

The agoecosystems of the country are facing various environmental stresses viz. salinity, submergence, diseases etc. Among the rice growing ecosystems, rainfed lowland is the most challenging one with respect to prevalence of many abiotic and biotic stresses. Among the biotic stresses, bacterial blight disease is one of the important factors in rainfed lowland rice ecosystems. Flash flood submergence is another important hazards to the agriculture of Bangladesh related to climate-change. Submergence stress regularly affects 15 millions hectares or more of RLR areas in South and Southeast Asia. (Neeraja et al., 2007). Recently, BRRI has released two flash flood tolerant rice varieties namely BRRI dhan51 and BRRI dhan52. But unfortunately, BRRI dhan52 has been found susceptible against bacterial blight both under field and controlled screening conditions. The advent of bacterial blight disease becomes more intensified under post-flood submergence condition. For this reason, the incorporation of $\mathrm{BB}$ resistant genes in the genetic background of BRRI dhan52 is inevitable. The bacterial blight resistant BRRI dhan52 will hopefully become wider adaptable in the farmers field condition increasing productivity of the flash flood prone areas of the country.

Recently the concept of MAS has provided an advantage of molecular markerbased approaches for crop improvement as compared to selection based solely on phenotype (Tanksley et al., 1989; Paterson et al., 1991). Current approaches and succcessful research to breeding disease resistant rice cultivars have integrated the use of molecular markers for selection of the desired traits. Gene-based markers for three important BB resistant genes viz. $x a 5, x a 13$ and $X a 21$ are now available. Recently, MAS has been extensively used to select the lines containing the BB resistant genes viz. $x a 5, x a 13$, and $X a 21$ using STS, CAPS and SSR markers (Chen et al., 2000; Chen et al., 2001; Sanchez et al., 2000; Singh et al., 2001 and Joseph et al., 2004).

Undoubtly, marker assisted backcrossing (MABC) is a precise and effective method to introgress a single locus controlling a trait of interest while retaining the essential characteristics of the recurrent parent (Collard and Mackill, 2008). MABC has three main advantages over conventional backcrossing. Firstly, DNA markers can be used for simple and efficient selection of the target locus ('foreground selection'). Secondly, the size of the donor chromosome segment containing the target locus can be minimized ('recombinant selection'). Thirdly, the recovery of the recurrent parent can be accelerated by selecting backcross lines with a higher proportion of recurrent parent genome ('background selection'). This approach has been purposefully used with great success for 
'enhancing' rice varieties for traits such as bacterial blight resistance gene $X A 21$; (Chen et al. 2000), the waxy locus for grain quality (Zhou et al., 2003) and submergence tolerance SUB1 (Neeraja et al., 2007; Septiningsih et al., 2009)

Considering the importance of submergence tolerance variety BRRI dhan52 to the Bangladesh rice economy and the necessity to introduce $\mathrm{BB}$ resistance, marker assisted backcross breeding techniques have been successfully used to introgress the Xa21 resistance gene and SUB1 QTL into this variety. Microsatellite markers are highly sequence specific and co-dominant. These promrant features make them ideal for use in background selection as they permit the detection of alleles coming from both parents and allow accurate determination of the allelic constitution of the offspring. Hence, a set of microsatellite markers were used that are polymorphic between the donor and recurrent parents in selection for the recurrent genome at backcross generation.

Finally, this work will certainly represent a successful example of the use of molecular markers, in foreground and background selection, for illuminatioy and pyramiding biotic and abiotic of genes of interest into a premium rice variety.

\section{Materials and Method}

Plant materials: IRBB60, a near isogenic line in the background of IR24, carrying the four resistant genes Xa4, xa5, xa13 and Xa21 served as the donor for all the crosses attempted. The recipient parents were BRRI dhan52 for each cross. This variety was derived from the cross BR11/IR40931-33-1-3-2. The variety was released by BRRI in 2010 as a submergence tolerant variety. Growth duration of this variety is 145 days on normal condition but it requires $155-160$ days during flash flood condition. The yield potential of this variety is 5 ton/ha under optimum management and 4.5 ton/ha if affected by 10-15 days flash flood.

\section{Molecular marker analysis}

For successfull molecular marker analysis salint proceedures that have been followed can be depicted bellow: DNA was extracted from young leaves of 2week-old plants using a modified protocol as described by Zheng et al., (1995). PCR was performed in $10 \mu 1$ reactions containing $25 \mathrm{ng}$ of DNA template, $1 \mu \mathrm{l}$ PCR buffer(10X), $0.2 \mu \mathrm{l}$ of $10 \mathrm{mM}$ dNTP, $0.50 \mu \mathrm{l}$ each of $10 \mu \mathrm{M}$ forward and reverse primers and $0.1 \mu \mathrm{l}$ of Taq DNA polymerase (5 U/ $\mu \mathrm{l})$ using 96-well GStorm thermal cycler. After initial denaturation for $5 \mathrm{~min}$ at $94^{\circ} \mathrm{C}$, each cycle comprised $45 \mathrm{sec}$ denaturation at $94^{\circ} \mathrm{C}, 45 \mathrm{sec}$ annealing at $55^{\circ} \mathrm{C}$, and $1: 30 \mathrm{~min}$ extension at $72^{\circ} \mathrm{C}$ with a final extension for $7 \mathrm{~min}$ at $72^{\circ} \mathrm{C}$ at the end of 35 cycles. The PCR products were mixed with bromophenol blue gel loading dye and were analyzed by electrophoresis on $8 \%$ polyacrylamide gel using mini vertical polyacrylamide gels for high throughput manual genotyping (CBS Scientific Co. Inc., CA, USA). The gels were stained in $0.5 \mathrm{mg} / \mathrm{ml}$ ethidium bromide and photos were taken using Alpha Imager 1220 (Alpha Innotech, CA, 
USA). Microsatellite or simple sequence repeat (SSR) markers were used for selection (IRGSP, 2005; McCouch et al., 2002; Temnykh et al., 2001).

For foreground selection, gene-based STS marker Xa21 specific to the bacterial blight resistance gene of Xa21 was used in the confirmation of Xa21 and STS marker ART5 was used for the confirmation of SUB1 QTL. ART5 was a genebased marker specific to the promoter region of putative SublC gene within SUB1 QTL (Septiningsih et al., 2009 and IRGSP, 2005).

A total of 4 (Xa21, ART5, RM8300 and Sub1C173) tightly linked and genebased foreground markers were surveyed over two parents viz. BRRI dhan52 and IRBB60. Two primers were obtained as polymorphic between two parents and two primers were monomorphic. Both the primers were used as gene-based markers initially in the foreground selection because of their clear codominant nature and capability of producing conspicuous bands. However, the individuals that were heterozygous for the foreground markers were selected in this selection step.

Microsatellite markers unlinked to $X a 21$ and SUB1 QTL covering all the chromosomes including the $\mathrm{Xa21}$ carrier chromosome 11 that were polymorphic between the two parents, were used for background selection to recover the recipient genome. Out of 304 SSR primers surveyed, a total of 61 microsatellite markers of the target QTL were used for background selection initially (Table 1).

Table 1. List of background markers of all 12 chromosomes used in the background selection

\begin{tabular}{lllllll}
\hline \multicolumn{1}{c}{ Chr 1 } & \multicolumn{1}{c}{ Chr 2 } & \multicolumn{1}{c}{ Chr 3 } & \multicolumn{1}{c}{ Chr 4 } & Chr 5 & Chr 6 \\
\hline RM495 & RM110 & RM231 & RM16301 & RM153 & RM540 \\
RM583 & RM211 & RM7 & RM119 & RM413 & RM587 \\
RM581 & RM423 & RM232 & & RM548 & RM510 \\
RM493 & RM341 & RM411 & & RM593 & RM314 \\
RM212 & RM208 & RM293 & & RM574 & RM402 \\
RM104 & & RM565 & & RM334 & RM527 \\
& & RM85 & & & RM340 \\
Chr 7 & Chr 8 & Chr 9 & Chr 10 & Chr 11 & Chr 12 \\
RM481 & RM337 & RM296 & RM228 & RM286 & RM4A \\
RM432 & RM407 & RM23778 & RM590 & RM5704 & RM511 \\
RM560 & RM152 & RM23901 & & RM229 & RM235 \\
RM336 & RM126 & RM23958 & & RM457 & RM12 \\
RM455 & RM72 & RM245 & & RM254 & \\
& RM5556 & & & & \\
& RM256 & & & & \\
\hline
\end{tabular}




\section{Data analysis}

Data analyses pertaining to obtain desirable results can be mentioned below: The molecular weights of the different alleles were measured using Alpha Ease Fc 5.0 software. The marker data was analyzed using the software Graphical Genotyper (GGT 2.0) (Van Berloo, 2008). The homozygous recipient allele, homozygous dominant allele and heterozygous allele were scored as ' $A$ ', ' $B$ ' and ' $\mathrm{H}$ '. The percent markers homozygous for recipient parent $(\% \mathrm{~A})$ and the percent recipient alleles $(\% \mathrm{R})$ were calculated.

\section{Results and Discussion}

\section{Results and Conconmitant relevant discussion can be mentioned below:}

$F_{1}$ and backcross seed production: DNA samples were collected from $75 F_{1}$ plants and PCR was carried out using Polymorphic SSR marker RM23958. According to PCR bands produced from the $75 \mathrm{~F}_{1}$ plants, 50 were scored as $\mathrm{H}$, 25 were scored as A. Score ' $\mathrm{H}$ ' represented heterozygous alleles for donor and recipient parent. Figure 1 shows the partial view of the gel picture of $F_{1}$ confirmation using SSR markers RM23958. The heterozygous $50 \mathrm{~F}_{1}$ 's were confirmed as true $\mathrm{F}_{1}$. A total of $2476 \mathrm{BC}_{1} \mathrm{~F}_{1}$ seeds were produced from $20 \mathrm{~F}_{1}$ plants.

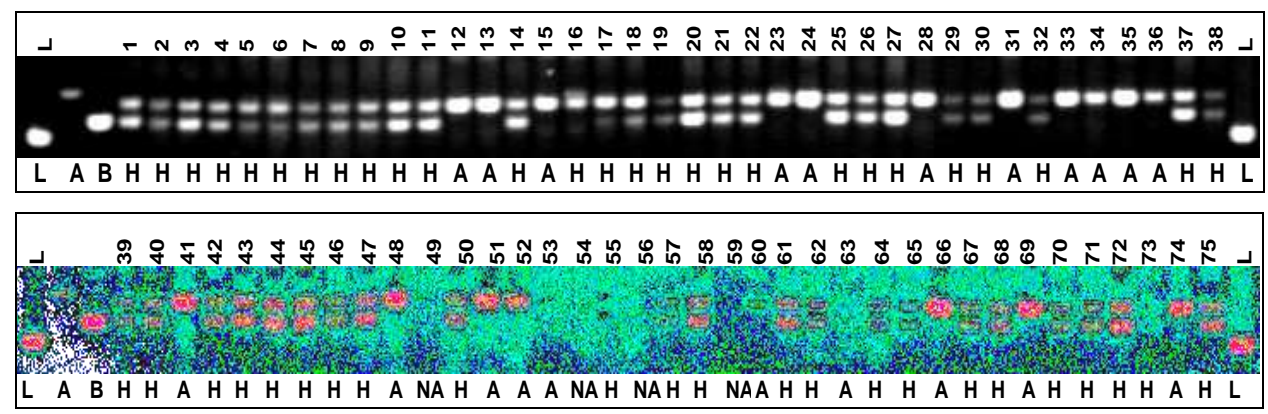

Fig.1 Confirmation of $F_{1}$ plants using SSR marker RM23958.

Foreground selection: Foreground selection was initially carried out by the gene-based marker Xa21 for Xa21 gene and gene-based marker ART5 for SUB1 QTL and the individual plants that were heterozygous at both the Xa21 and SUB1 loci were identified reducing the population size for further selection. Out of 72 plants, 30 plants were found showing the locus for the gene-based marker Xa21 as heterozygous state (Score H), 41 plants were found with the locus fixed for recipient allele (susceptible allele) (Score A). Here, in $\mathrm{BC}_{1} \mathrm{~F}_{1}$ generation, 30 plants showed ' $\mathrm{H}$ ' score and 41 plants showed 'A' score which indicated that the results fitted to the expected 1:1 ratio of this generation with a non-significant chi square value of 1.718 at a probability level of 0.05 . The single plants with $B$ score were produced due to accidental failure of backcrossing. 
Out of 30 heterozygous plants for Xa21, 23 plants were used in foreground selection for the detection of SUB1 QTL by using ART5 marker. 11 plants were found showing the locus for the gene-based marker as heterozygous state (Score $\mathrm{H}), 12$ plants were found with the locus fixed for recipient allele (susceptible allele) (Score A). Figure 2 and 3 showed the foreground selection of $\mathrm{BC}_{1} \mathrm{~F}_{1}$ generation.

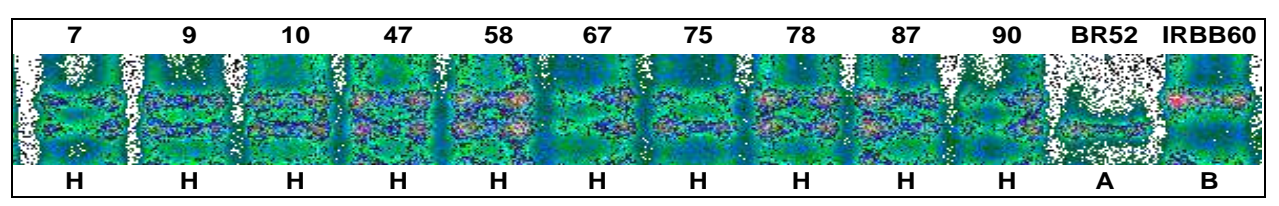

Fig. 2. Complete view of gel picture of the foreground selection with the gene-based marker $\mathrm{Xa}_{21}$ in $\mathrm{BC}_{1} \mathrm{~F}_{1}$ plants.

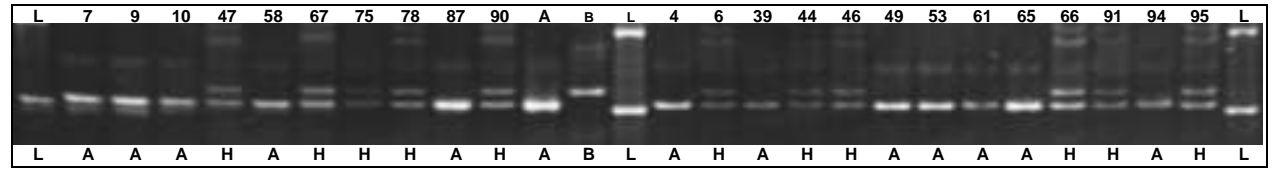

Fig. 3. Gel picture of the foreground selection using marker ART5 in population of $\mathrm{BC}_{1} \mathrm{~F}_{1}$ generation.

Background Selection: A total of 61 microsatellite markers were used for background selection over $10 \mathrm{BC}_{1} \mathrm{~F}_{1}$ plants resulting from foreground selection. The percent markers homozygous for the recipient parent ranged from 37.70 to $57.37 \%$ in those 10 plants (Table 2). In the plant number 78 and 90 (Table 2) of $\mathrm{BC}_{1} \mathrm{~F}_{1}$ generation, 35 markers out of 61 markers $(57.37 \%)$ were like recipient parent type. But if the alleles of the homologous chromosomes were considered, the percentage of recipient alleles in plant number 78 and 90 was $78.7 \%$. So, these two plants had been considered as the best plants of that population. Figure 4 shows the graphical genotype of the best plant 78 .

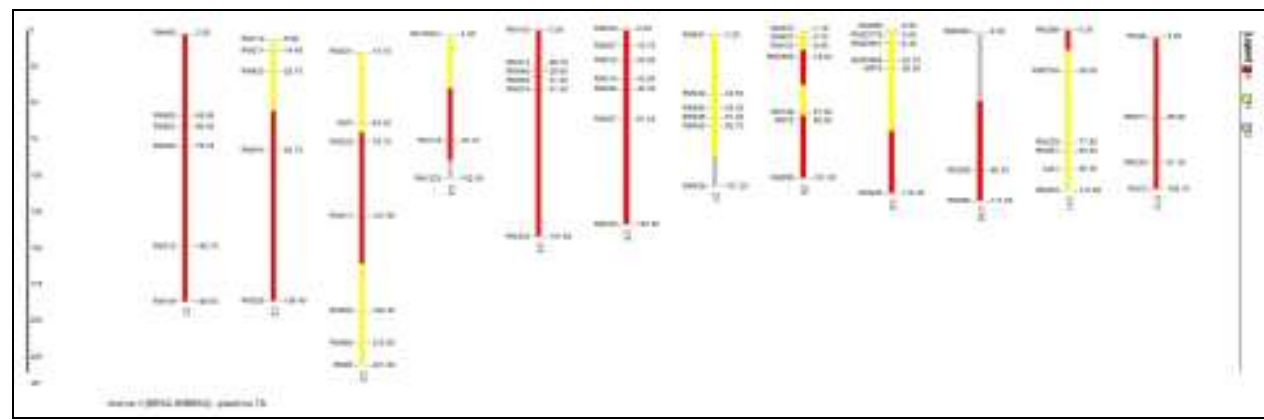

Fig. 4. Graphical genotype of the selected best plant 78 of $\mathrm{BC}_{1} \mathrm{~F}_{1}$ generation. The red coloured regions on the chromosomes indicated homozygous region for the recipient genome while the yellow coloured regions indicated the heterozygous regions and the gray coloured regions indicated unknown region. The distances were represented in $\mathrm{cM}$ based on published map of Temnykh et al. (2001). 
Table 2. Results of background selection, $\mathrm{BC}_{1} \mathrm{~F}_{1}$ generation (No. of markers homozygous for recipient $\mathrm{A}$, donor $\mathrm{B}$, or heterozygous $\mathrm{H}$ )

\begin{tabular}{l|cccccccccc}
\hline \multicolumn{1}{c|}{ Items } & \multicolumn{10}{c}{ Plant Numbers } \\
\hline & 6 & 44 & 46 & 47 & 67 & 75 & $\mathbf{7 8}$ & $\mathbf{9 0}$ & 91 & 95 \\
A & 31 & 31 & 25 & 30 & 23 & 25 & 35 & 35 & 30 & 24 \\
H & 29 & 27 & 35 & 31 & 37 & 36 & 26 & 26 & 29 & 36 \\
B & 0 & 1 & 0 & 0 & 1 & 0 & 0 & 0 & 0 & 0 \\
$\%$ A & 51.67 & 53.1 & 41.66 & 49.18 & 37.70 & 40.98 & 57.37 & 57.37 & 50.8 & 40.0 \\
$\%$ & $\mathbf{7 5 . 8 3}$ & 76.72 & 70.83 & 74.6 & 69.2 & 70.5 & $\mathbf{7 8 . 7}$ & $\mathbf{7 8 . 7}$ & $\mathbf{7 5 . 4}$ & 70.0 \\
Recipient & & & & & & & & & & \\
allele & & & & & & & & & & \\
Rank & $\mathbf{2}$ & 8 & 5 & 4 & 9 & 6 & $\mathbf{1 a}$ & $\mathbf{1 b}$ & $\mathbf{3}$ & 7 \\
\hline
\end{tabular}

BRRI dhan52 is a medium slender grain submergence tolerant indica rice variety which can tolerate 10-15 days flash flood condition and yield potential is 4.5 to 5.0 ton/ha. In the present work, we have introgressed BB resistant gene Xa21 and confirm the presence of SUB1 QTL in BRRI dhan52 with the objective of developing BB resistant BRRI dhan52-Xa21 line that retain the yield and quality characteristics of BRRI dhan52.

Although the average percentage of the recurrent parent genome is $75 \%$ for the entire $\mathrm{BC}_{1} \mathrm{~F}_{1}$ population, some individuals possess more or less of the recurrent parent genome than others (Collard et al., 2008). Our selected $\mathrm{BC}_{1} \mathrm{~F}_{1}$ plants had a recurrent parent genome than that of expected $75 \%$.

In Foreground as well as and Background selection, selection of $\mathrm{BC}_{1} \mathrm{~F}_{1}$ generation was completed and the best plants identified possessed $79 \%$ recipient parent genetic background along with the target genes in the heterozygous state. The recovery of recipient parent genome in the best plant indicated that one more backcrossing and a final self pollination in the backcross- $\mathrm{F}_{2}$ generation would be required in order to develop BRRI dhan52-Xa21 homozygous line.

The current output of marker-assisted backcrossing activities of this work reflected that the approaches could be routinely used in order to pyramid multiple genes or QTLs, conferring tolerances or resistances to multiple biotic and abiotic stresses, into the genetic background of high yielding varieties and also it could be helpful to achieve wider adoption of the newly developed variety in the flash flood prone ecosystem of the country where there are outbreaks of bacterial blight disease.

\section{References}

Chen, S., X. H. Lin, C. G. Xu and Q. F. Zhang. 2000. Improvement of bacterial blight resistance of 'Minghui 63', an elite restorer line of hybrid rice, by molecular markerassisted selection. Crop Sci. 40: 239-244. 
Chen, S., C. G. Xu, X. H. Lin and Q. F. Zhang. 2001. Improving bacterial blight resistance of ' 6078 ' an elite restorer line of hybrid rice, by molecular marker-assisted selection. Plant Breeding. 120: 133-137.

Collard, B. C. Y., K. M. Iftekharuddaula, M. J. Thomson, A. M. Pamplona and D. J. Mackill DJ. 2008. An electronic manual on marker assisted backcrossing in rice: theory and applications. 1st edition. GCP Wiki, International Rice Research Institute,Manila,Philippines.(http://mcclintock.generationcp.org/index.php?option=c om_content\&task=view\&id=92\&Itemid=114)

Collard, B. C.Y. and D. J. Mackill .2008. Marker-assisted selection: an approach for precision plant breeding in the 21st century. Phil Trans Royal Soc B Rev. 363: 557-572.

IRGSP. 2005. The map-based sequence of the rice genome. Nature. 436: 793-800.

Joseph, M., S. Gopalakrishnan, R. K. Sharma, V. P. Shinh, A. K. Singh, N. K. Singh and T. Mohapatra. 2004. Combining bacterial blight resistance and Basmati quality characteristics by phenotypic molecular marker-assisted selection in rice. Molecular Breeding. 13: 377-387.

Khush, G. S., D. J. Mackill and G. S. Sidhu. 1989. Breeding rice for resistance to bacterial blight. Bacterial Blight of Rice. Proceedings of the International Workshop on Bacterial Blight Rice, IRRI, Manila, Philippines. P. 207-217.

McCouch, S. R., L. Teytelman, Y. Xu, K. B. Lobos, K. Clare, M. Walton, B. Fu, R. Maghirang, Z. Li, Y. Zing, Q. Zhang, I. Kono, M. Yano, R. Fjellstrom, G. DeClerck, D. Schneider, S. Cartinhour, D. Ware D and L. Stein L. 2002. Development and mapping of 2240 new SSR markers for rice (Oryza sativa L.). DNA Res. 9: 199-207.

Neeraja, C. N., R. Maghirang-Rodriguez, A. Pamplona, S. Heuer, B. C. Y. Collard, E. M. Septiningsih, G. Vergara, D. Sanchez, K. Xu, A. M. Ismail and D. J. Mackill. 2007. A marker-assisted backcross approach for developing submergence-tolerant rice cultivars. Theor Appl Genet. 115: 767-776.

Paterson, A. H., S. D. Thanksley and M. E. Sorrels. 1991. DNA marker in plant improvement. Adv Agron. 46: 39-89.

Reyes, R. C., C. M. Vera Cruz, T. C. Aballa, M. R. Baraiodan and T. W. Mew. 1983. Bacterial disease of rice. In: Rice production manual. Laguna (Philippine). UPLB College of Agriculture. P. 341-352.

Sanchez, A. C., B. Fu, D. Yang, G. S. Khush and Z. Li. 2000. Isolation and sequence analysis of candidate cDNA clones for the Xa-5 gene in rice. International Congress on Plant Molecular Biology (ICPMB) June 18-24, at Quebec, Canada. Abstracts published by ICPMB.

Septiningsih, E. M., A. M. Pamplona, D. L. Sanchez, C. N. Neeraja, V. G.Vergara, S. Heuer, A. M. Ismail and D. J. Mackill. 2009. Development of submergence tolerant rice cultivars: The Subl locus and beyond. Ann Bot. 103: 151-160.

Singh, G. P., M. K. Srivastava, R. V. Shing and R. M. Singh. 1997. Variation and qualitative losses caused by bacterial blight in different rice varieties. Indian Phytopathol. 30: 180-185.

Singh, S., J. S. Sidhu, N. Huang, Y. Vikal, Z. Li, D. S. Brar, H. S. Dhaliwal and G. S. Khush. 2001. Pyramiding three bacterial blight resistance genes (xa5, xal3 and 
Xa21) using marker-assisted selection into rice cultivar PR106. Theor Appl Genet. 102: 1011-1115.

Tanksley, S. D., N. D. Young, A. H. Paterson and Bonierbale. 1989. RFLP mapping in plant breeding: New tools for an old science. Biotechnology. 7: 257-264.

Temnykh, S., G. DeClerck, A. Lukashov, L. Lipovich, S. Cartinhour and S. McCouch. 2001. Computational and experimental analysis of microsatellites in rice (Oryza sativa L.): Frequency, length variation, transposon associations, and genetic marker potential. Genome Res. 11: 1441-1452.

Van Berloo, R. 2008. GGT 2.0: Versatile software for visualization and analysis of genetic data. Journal of Heredity. 99: 232-236.

Zhai, W. X. and L. H. Zhu. 1999. Rice bacterial blight resistance genes and their utilization in molecular breeding. Adv Bitecnol. 19: 9-15.

Zheng, K., P. K. Subudhi, J. Domingo, G. Magpantay and N. Huang. 1995. Rapid DNA isolation for marker assisted selection in rice breeding. Rice Genet Newsl. 12: 255-258.

Zhou, P. H., Y. F. Tan, Y. Q. He, C. G. Xu and Q. Zhang. 2003. Simultaneous improvement for four quality traits of Zhenshan 97, an elite parent of hybrid rice, by molecular marker-assisted selection. Theor Appl Genet. 106: 326-331. 
